\title{
Research on Industrial Product Design and Art Design
}

\author{
Jianying Xin \\ School of Art \& Design, Hankou College, Wuhan, Hubei, 430070
}

Keywords: Industrial Product, Art Design, Color

\begin{abstract}
From the perspective of culture, the original creation of mankind is the most essential cultural phenomenon, "the yuan culture"; from the perspective of art culture, the creation of culture is the creation of art and culture. Created art is an extraordinary form of art culture, is the visual arts language. As the continuation and development of human activities, industrial product design is also an art culture. The essence of industrial product design is to use the art of modeling language embodies the creature culture, is the artistic quality of cultural activities.
\end{abstract}

\section{Introduction}

The creation of human beings, is the creative nature of mankind to obtain a natural nature of the original form, seeking to survive in nature, is the most essential cultural phenomenon. Created culture is a material culture and spiritual culture or between the decomposition of the culture, with a primary and comprehensive, is the "culture". A human cultural history, no matter in which region and nation, are from the production of production tools and daily necessities began. Mankind in the fight for the first stone as a tool when it is "practical before the aesthetic" For "labor", conducive to "survival" of the practical purpose. Therefore, from the earliest sense, the creation of activities is comprehensive, general, practical. However, the general artifacts as a material appears, it will have a certain practical function; as the existence of the material, it will have a mental impact on people. After the practical purpose of "labor" and "survival" has been achieved, mankind begins to have the "art" and "aesthetic" considerations, and the general artifact rises to the art of creation. In the long history, with the human "art" and "aesthetic" to consider more and more rich, man-made gradually derived from the separation of the so-called "pure art", thus the formation of art and culture, so that appeared "Material culture" and "spiritual culture" of the division. However, the creation of culture as a primary "mother" and no disintegration, but along the path of their own development.

Great world, a variety of creation art is commonplace. However, when we live in all the needs of the complete environment, all-in-one contact with the existence of the art of creation are considered right and proper, so we will turn a blind eye to them, the artifacts of the "mother" status also Ignore the abstract: the art of this art simply into the "material culture", dismissed as artisans, and excluded from the art and aesthetics. Especially since the country since the Qin Dynasty, to follow the metaphysical way to the metaphysical device for the tan. This kind of "heavy light" thought followed in the past, not only a large number of artists, artisans get the economic status and social status, as a culture of cultural activities did not in the overall sense of the corresponding recognition and attention. "The gentleman who is not even", I do not know how many people.

\section{Art Product Design Content of Industrial Products}

Industrial product design is the industrial products, materials, structure, technology, shape, color, surface treatment, decoration and other factors from the social, economic, technical and other aspects of comprehensive treatment, it is necessary to meet the requirements of the product material function, But also to meet the needs of people's aesthetic taste. That is, in the design of industrial products, not only to explore the possibility of industrial products manufacturing, operability, but also to explore the art of morphological performance. The "artistry" here includes product modeling, color, ornamentation, and visual effects related to structural processing and texture effects 
processing. Industrial product design is also the materialization of human creation, in becoming a kind of art of creation at the same time, it has become a visual language art. We usually refer to what the beauty of the eye through the eye as "visual art" or "space art", so the art of creation is a visual language art. General art is reflected by the specific language form, where the art of creation art is the specific form of artifacts, color, texture, etc., can be appreciated through the visual experience and recognition. Industrial product design, as the continuation and development of human activities, is also an art culture, is a form of artistic language.

The former "Industrial Design and Scientific Research Institute of the Soviet Union" Director Yuri Suroviev once the industrial design evaluation of human "second culture" Abstract: "subordinate to culture, that is, from a variety of products to create the 'second culture', Which reflects the complexity and conflict of all the results produced by the differences between the socio-economic system, the concept of consciousness and the contradiction between material and spiritual, and the advantages and disadvantages of the industrial design and its achievements (products) And the socio-economic form and its design to adapt to the social and cultural separation to consider, it is impossible. "Therefore, on the one hand, industrial product design must rely on the specific cultural environment; the other hand, industrial product design itself, Also created a culture. The essence of industrial product design, that is, with the art of modeling language embodies the creature culture, is the artistic quality of cultural activities.

Product color design and product attributes are closely related, for example, China engaged in the postal service industry, "by the B political green 'can be said that the typical image of our postal service, its work clothing color, transport and so on with this green. Therefore, the product color attribute research in addition to the color attribute "hue, lightness, purity of the basic research, the more Miao is to understand the product industry color and the industry's standardization of the color of the product, out of the industry color limit of the product color in the social recognition may be subject to greater risk. In addition, the traditional products of the traditional velvet characteristics of the current characteristics of research and analysis, summed up, the rational introduction of the product color design trends for product color innovation to provide effective design reference. Color of the three ass is the basis of all color design, the rational use of color 3 attributes to create a rich and colorful product design. The traditional color of the product, the product of the industry color and industry standard color of the limited in a certain period of time is relatively stable, but with the changes in the powder era, technological progress, fashion and fashionable gradient.

\section{Product Art Design Direction and Method}

The overall coordination of color is an important factor in the performance of the artistic beauty of the product. In the narrow sense, the art design of the product color is from the aesthetic point of view, through the color measures to make the product has a visual beauty, that is, the decorative effect of the product color; Speaking from the design point of view, pay attention to the use of color art and rationality, more emphasis on the color of the functionality. Product color design process must consider the use of the product environment, so that the color of the product and its work in which the environment in line with the closed. Such as the prompt, local design with eye-catching colors, prompting people to operate easy to use, and deliberately attract people's attention. The main design uses eye-catching colors, attract people's attention, visual impression. In addition to other environmental colors in sharp contrast, can play a clear role, such as yellow, orange life jackets; some specialized products with general color, such as warning signs, report lights, etc.

Common sense, the design is generally not changed. The broad product color art design covers multiple layers of product color design, including artistic design of color, rational design and innovative design. The use of color memory, symbol, sense of transmission and other functions can effectively improve the aesthetic value of product art and the use of value.

The art of color design includes artistic design and rational design. The artistic design of the color of the product refers to the artistic beauty of the product, the image of the product and the image of the Lu-brand by combining the different colors into the production of Lu by contrasting the work of harmony, balance, proportioning and rhythm rhythm. The rational design of the product 
color refers to the correct choice of color according to the material, the use function, the use of loop, man-machine characteristics, processing technology, production cost and other comprehensive elements and specific design requirements. In the color design of the product, the choice of color should be based on the rationality of color design to highlight the art of color processing - artistic design, which color and product color style is to grasp the color art design of the main aspects.

Color of product color. The color of the product color should be based on the function of the product color, taking into account the two aspects of "highlighting" and "integrating" both the prominent aspect and the smoothing aspect of the product. The product color scheme should be grasped: Contrast, highlight the focus of the product, such as the phone keys and display; inhibit the main color of the product, the use of `bright spots. Design to steal the importance of a particular product to improve product operability, such as lathe control switch; The use of contrast color (complementary color) to enhance the contrast, the use of quasi-contrast color (deviation from the color of color) is contrast and smooth coexistence; the use of ultra-strong ability to deal with the colorless. Black. And universal harmony color 'white ', black regardless of any Color bath can play a role in upgrading, which is why the black phone is more popular reasons, and white can make the contrast while highlighting the overall effect.In addition, the metal-like silver can also be a good and a variety of Color to measure, with silver as the main color of electronic products by consumers generally recognized prominent 'product color scheme design to enhance the 3 attribute comparison, and "financial Type 'color scheme impaired color contrast effect in the design should be. 'Fusion 'product color method is as follows:

Use the same color, so that the product is unified and harmonious, designed to grasp the color difference between the changes, such as the color difference between the small color to produce a stable, warm, soft product art effect Li Ming Ming unified, to create a sense of product stability; use of color to shape the product, For example, from the same velvet near the hue out of the two tones of the "two-tone" combination, the production of color difference, velvet is a combination of into the faint, can create a rich color table lazy.

Product color design and product style design. Product color design if the product can not be consistent with the form, and then no color of the beautiful color, color image shape is an important element of product style. The three elements that usually determine the color of the product are hue, hue, and contrast. One of the most important is the color, even with the same product, when the color of the tone changes, the product will show a very different style. Figure 2 for the concept of mini-washing machine design, using different colors, the product style is significantly different. The color is relatively straightforward, for example, in the use of high-purity color on the product color, especially the 3 primary colors, which will highlight the design features of the basin product, while the purple, both the shades, product style. Compared with the same color, hue, product color design to enhance the contrast can increase product vitality, contrary to reduce the relationship between the relationship will create a stable product style. In addition, "contrast. Can be philosophized as a product color, style design art processing techniques, through the brightness contrast, purity contrast, color contrast, color contrast and area contrast and other means of integrated use, to achieve the harmonious design of product color. Design to consider the dynamic state of the product under the state of change, such as the color of the display, the color of the work interface, as well as the work of the color changes should also be coordinated with the main color of the product, in order to further shape the art of the product style.

\section{Conclusion}

Large industrial products are not only designed to meet the demands of the self-sufficient and narrow range of groups, but for the purpose of a broad market. In the processing technology mechanization at the same time, with the progress of science and technology, new materials are also emerging, the past does not exist in a variety of industrial products gradually into the human life, the past has not been art tools appear in the industrial products, Industrial product design to the whole society to popularize and penetrate. Today, plastics, cars and television have been deeply rooted in modern life, and we have gradually ignored the essence of industrial product design. 


\section{References}

[1] Wu Zhuobin. Analysis of modern industrial product design in the rational integration of ethnic elements [J]. Western Leather. 2017 (12)

[2] Huang Lu. The use of traditional culture in industrial product design [J]. Art Technology. 2017 (04)

[3] Xing Penghua. On the green design in industrial product design application [J]. Design. 2017 (13)

[4] Wang Li. Traditional cultural elements in the industrial product design innovation application [J]. Packaging Engineering. 2017 (16)

[5] Liu Che. Color composition in the industrial product design application [J]. Tomorrow fashion. 2017 (05)

[6] Wang Xuanyu. Traditional culture in the industrial product design application [J]. Tomorrow fashion. 2017 (05) 